\title{
Implementasi Metode Analytical Hierarchy Process Untuk Penentuan Aplikasi Berbasis Enterprise Resources Planning
}

\author{
Willy Hihola'), Santoso Setiawan ${ }^{2 *}{ }^{*}$, Fitri Latifah ${ }^{3)}$, Ummu Radiyah $^{4)}$ \\ 1) 2)Program Studi Sistem Informasi, STMIK Nusa Mandiri \\ 3) 4)Program Studi Teknik Informatika, STMIK Nusa Mandiri \\ ${ }^{*}$ Correspondence Author: santoso.sts@nusamandiri.ac.id, Jakarta, Indonesia \\ DOI: https://doi.org/10.37012/jtik.v7i1.500
}

\begin{abstract}
Abstrak
Enterprise Resources Planning atau ERP adalah kumpulan dari beberapa sistem aplikasi yang saling terintegrasi. Namun tidak semua sistem aplikasi yang ada di ERP tersebut sesuai atau cocok dengan yang dibutuhkan perusahaan pemakai, kendala biaya menjadi salah satu pertimbangannya. Oleh karena itu dibutuhkan penelitian dengan metode yang tepat agar hasilnya bisa digunakan untuk menjadi bahan pertimbangan dalam memutuskan atau menentukan sistem aplikasi mana sajakah yang benar-benar dibutuhkan oleh perusahaan tersebut yang sesuai dengan jenis bidang usahanya. Metode Analytical Hierarchy Process atau AHP adalah salah satu metode dalam sistem pendukung keputusan. Setelah dilakukan penelitian dengan metode AHP yang dimulai dari identifikasi masalah, studi literatur, kriteria pemilihan aplikasi berbasis ERP, pengumpulan data sekunder dan primer, hingga pengolahan data, diperoleh jenis aplikasi berbasis ERP yang diminati oleh user. Hasil tersebut dapat membantu pihak manajemen dalam menentukan aplikasi berbasis ERP mana yang akan digunakan oleh pihak perusahaan.
\end{abstract}

Kata kunci: Analytical Hierarchy Process (AHP), Enterprise Resources Planning (ERP), Sistem Pendukung Keputusan.

\begin{abstract}
Enterprise Resources Planning or ERP is a collection of several integrated application systems. However, not all application systems in the ERP are suitable or match the needs of the user company, cost constraints are one of the considerations. Therefore, research with the right method is needed so that the results can be used as consideration in deciding or determining which application systems are really needed by the company in accordance with the type of business field. The Analytical Hierarchy Process or AHP method is one of the methods in decision support systems. After conducting research with the AHP method, starting from problem identification, literature study, ERP-based application selection criteria, secondary and primary data collection, to data processing, so that the types of ERP-based applications that are of interest to users are obtained. These results can help management in determining which ERP-based applications the company will use.
\end{abstract}

Keywords: Analytical Hierarchy Process (AHP), Enterprise Resources Planning (ERP), Decision Support System.

\section{PENDAHULUAN}

Berkembangnya sebuah usaha yang membuat produktivitas meningkat ialah tantangan dalam dunia bisnis (Tantangan, Sosial Banuprasetyo, \& Trisyanti, 2018), bukan hanya merupakan kesempatan untuk membuat bisnis semakin besar namun dibalik semua itu tantangan perusahaan akan ketepatan, kedisiplinan serta efisiensi produksi akan sangat diuji. Dengan menggunakan sistem manual tidak akan mudah untuk mendapatkan efisiensi yang diinginkan perusahaan (Khasanah, Raharjo, 2017). 
Untuk memodernisasi metode lama tersebut, maka dibuatlah Enterprise Resources Planning (ERP) yang berfungsi menyatukan atau mengintegrasikan proses bisnis dalam suatu perusahaan dan memiliki basis data yang sama. Dengan satu basis data yang digunakan, maka setiap divisi atau departemen akan menggunakan informasi yang sama. Hal ini berarti meningkatkan efisiensi dibandingkan jika setiap divisi memiliki data sendiri-sendiri. Selain itu akurasi data juga dapat lebih terjaga dikarenakan data yang ada terpusat (Suminten, 2019).

Meskipun ERP dapat membantu menyelesaikan kegiatan operasional perusahaan, tetapi harga aplikasi berbasis ERP tidaklah murah, sehingga perusahaan yang ingin menerapkan aplikasi berbasis ERP harus mempertimbangkan dengan baik aplikasi berbasis ERP yang sesuai dengan kebutuhan.

Untuk menunjang pimpinan atau manajer dalam memilih sistem ERP yang sesuai diperlukan suatu metode pendukung keputusan yang handal, dimana sistem pendukung keputusan tersebut harus dapat memberikan perbandingan kriteria dan alternatif dari setiap jenis aplikasinya. Salah satu metode pendukung keputusan tersebut adalah Analytical Hierarchy Process (AHP). Beberapa manfaat yang dapat di peroleh dari penggunaan AHP antara lain: a) memadukan intuisi, pemikiran, perasaan dan penginderaan dalam menganalisis pengambilan keputusan, b) memperhitungkan konsistensi dari penilaian yang telah dilakukan dalam membandingkan faktor-faktor yang ada, c) memudahkan pengukuran dalam elemen.

AHP telah banyak digunakan dalam penelitian yang berkaitan dengan sistem pengambilan keputusan. berikut ini terdapat beberapa penelitian yang dapat di jadikan referensi dalam penerapan AHP, diantaranya adalah; "Integrated Supplier Selection Framework in a Resilient Construction Supply Chain: An Approach via Analytic Hierarchy Process (AHP) and Grey Relational Analysis (GRA)", oleh Ting-Kwei Wang (Wang, Zhang, Chong, \& Wang, 2017), "Water resource vulnerability assessment in Rawalpindi and Islamabad, Pakistan using Analytic Hierarchy Process (AHP)", Rabia Shabbir (Shabbir \& Ahmad, 2016), "Dismissal Working Relationship using Analytic Hierarchy Process Method", oleh Andino Maseleno (Maseleno, Rizqi Al Akbar, \& Fitrian, n.d.), dan penelitian yang berjudul "Are MCDM methods useful? A critical review of Analytic Hierarchy Process (AHP) and Analytic Network Process (ANP)", oleh Mehdi Rajabi Asadabadi (Asadabadi, Chang, \& Saberi, 2019).

Dengan adanya kriteria-kriteria dan alternatif-alternatif yang disertakan dalam perhitungan di metode AHP (Putra, Kusrini, \& Pramono, 2019) maka keluaran yang di hasilkan dari 
perhitungan AHP dapat memberikan pertimbangan yang lebih baik sehingga tujuan yang diinginkan yaitu memudahkan dalam pengambilan keputusan dalam menentukan jenis aplikasi berbasis ERP yang sesuai dengan kebutuhan pemakai dapat terpenuhi.

\section{METODE}

Berikut ini tahapan penelitian yang dilakukan:

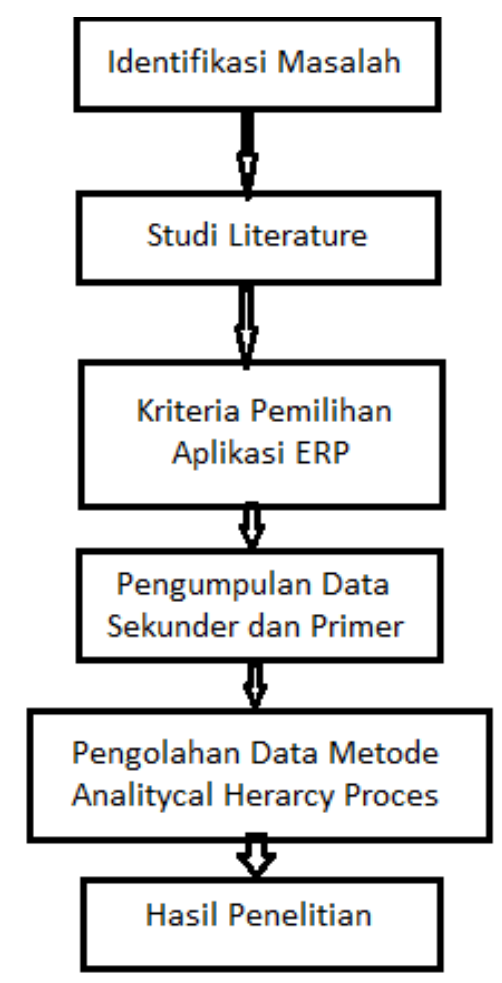

Gambar 1. Tahapan Penelitian

Sumber data yang digunakan dalam tahap ini yaitu data-data yang ada di PT. RMM Solutions.

Ada beberapa dasar yang harus dipahami dalam menyelesaikan persoalan dengan menggunakan metode AHP, diantaranya:

\section{A. Decompotition}

Mendefinisikan persoalan dengan cara memecah persoalan yang utuh menjadi unsur-unsur dan digambarkan dalam bentuk hirarki.

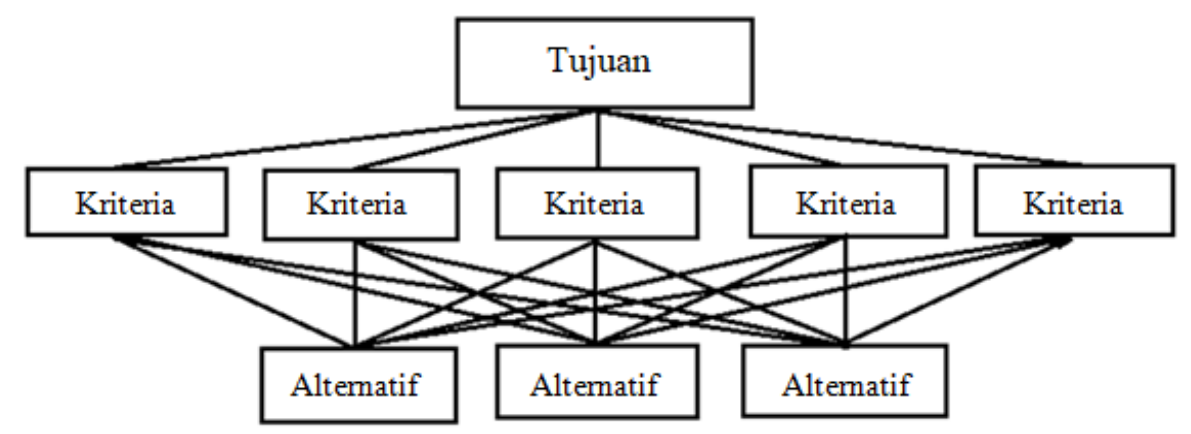

Gambar 2. Contoh Hirarki AHP (Analytical Hierarchy Process) 


\section{B. Comparative Judgement}

Langkah pertama menentukan prioritas elemen dengan membuat perbandingan berpasangan, yaitu membandingkan elemen secara berpasangan sesuai kriteria yang diberikan. Matriks perbandingan berpasangan diisi menggunakan bilangan untuk membuat penilaian tentang kepentingan relatif dua elemen dan dituliskan dalam bentuk matriks perbandingan berpasangan (pairwise comparison).

Tabel 1.

Matriks Perbandingan Berpasangan

\begin{tabular}{cccc}
\hline Tujuan & Elemen A & Elemen B & Elemen C \\
\hline Elemen $\mathrm{A}$ & & & \\
\hline Elemen B & & & \\
\hline Elemen C & & & \\
\hline
\end{tabular}

\section{Syntesis of Priority}

Dari matriks pairwise comparison kemudian dicari eigen vektor untuk mendapatkan local priority. Pertimbangan terhadap perbandingan berpasangan disintesis untuk memperoleh global priority. Hal-hal yang dilakukan dalam langkah ini adalah:

1. Menjumlahkan nilai dari setiap kolom pada matriks.

2. Membagi setiap nilai dari kolom dengan total kolom yang bersangkutan untuk memperoleh normalisasi matriks.

3. Menjumlahkan nilai dari setiap baris dan membagi dengan jumlah elemen untuk mendapatkan nilai rata-rata.

\section{Consistency}

Dalam pembuatan keputusan, mengetahui seberapa baik konsistensi merupakan hal yang penting karena penelitian tidak menginginkan keputusan berdasarkan pertimbangan dengan konsistensi yang rendah. Untuk itu, beberapa hal yang dilakukan dalam langkah ini adalah sebagai berikut:

1. Lakukan perkalian setiap nilai pada kolom pertama dengan prioritas relatif elemen pertama, nilai pada kolom kedua dengan prioritas relatif elemen kedua dan begitu seterusnya.

2. Jumlahkan setiap baris yang ada.

3. Hasil dari penjumlahan baris dibagi dengan elemen prioritas relatif yang besangkutan.

4. Jumlahkan hasil bagi dengan banyaknya elemen yang ada, kemudian hasilnya disebut $\lambda$ maks

5. Hitung Consistency Index $(\mathrm{CI})$ dengan rumus

$$
\mathrm{CI}=(\lambda \text { maks }-\mathrm{n}) /(\mathrm{n}-1)
$$

Keterangan:

$\mathrm{n}=$ banyaknya elemen 
6. Hitung Consistency Ratio (CR) dengan rumus

$$
\mathrm{CR}=\mathrm{CI} / \mathrm{RI}
$$

Keterangan:

$$
\begin{aligned}
& \mathrm{CR}=\text { Consistency Ratio } \\
& \mathrm{CI}=\text { Consistency Index } \\
& \mathrm{RI}=\text { Random Consistency Index }
\end{aligned}
$$

7. Memeriksa konsistensi hirarki

Jika nilainya lebih dari 10\%, maka penilaian data judgement harus diperbaiki. Namun jika ratio konsistensi (CI/RI) kurang atau sama dengan 0,1 maka hasil perhitungan dapat dinyatakan benar.

\section{HASIL DAN PEMBAHASAN}

Kriteria yang digunakan untuk menentukan aplikasi terbaik berbasis ERP, adalah sebagai berikut:

1. Usefull: sistem harus dapat mengcover kegiatan bisnis berjalan berdasarkan kesepakatan yang ada.

2. User friendly: struktur dan operasinya mudah dimengerti dan prosedur mudah diikuti.

3. Realtime: sistem dapat menghasilkan informasi yang tepat waktu.

4. Fleksibilitas: sistem dapat menampung perubahan-perubahan pada bisnis proses yang ada.

5. Ekonomis: sistem harus dapat memberikan nilai tambah

Sedangkan alternatif untuk menentukan aplikasi terbaik berbasis ERP, adalah

1. Finance

2. Travel Management

3. Warehouse Management

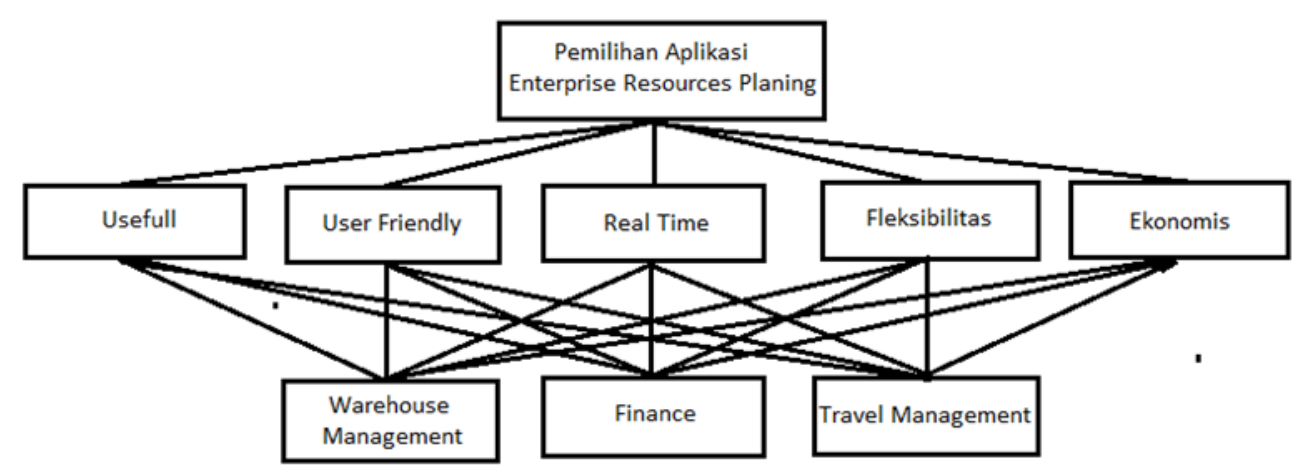

Gambar 3. Hirarki AHP (Analytical Hierarchy Process)

Data yang digunakan pada penelitian ini berasal dari koesioner yang diisi oleh 7 responden yang berasal dari karyawan pada PT RMM Solution. Penghitungan awal dimulai dengan membuat matrik berpasangan untuk kriteria utama. 


\section{Tabel 2.}

Penjumlahan Matrik Berdasarkan Kriteria Utama

\begin{tabular}{lccccc}
\hline \multicolumn{1}{c}{ Kriteria } & Usefull & Userfriendly & Realtime & Fleksibilitas & Ekonomis \\
\hline Usefull & 1,00 & 1,93 & 1,29 & 1,83 & 0,57 \\
\hline Userfriendly & 0,91 & 1,00 & 0,77 & 1,38 & 0,69 \\
\hline Realtime & 0,77 & 1,29 & 1,00 & 0,65 & 0,37 \\
\hline Fleksibilitas & 0,55 & 0,72 & 1,54 & 1,00 & 1,13 \\
\hline Ekonomis & 1,76 & 1,45 & 2,72 & 0,89 & 1,00 \\
\hline \multicolumn{1}{c}{ TOTAL } & 4,99 & 6,39 & 7,33 & 5,75 & 3,75 \\
\hline
\end{tabular}

Tabel 3.

Normalisasi Matrik Berdasarkan Kriteria Utama

\begin{tabular}{lcccccc}
\hline \multicolumn{1}{c}{ Kriteria } & Usefull & Userfriendly & Realtime & Fleksibilitas & Ekonomis & Rata-rata \\
\hline Usefull & 0,20 & 0,30 & 0,18 & 0,32 & 0,15 & 0,23 \\
\hline Userfriendly & 0,18 & 0,16 & 0,11 & 0,24 & 0,18 & 0,17 \\
\hline Realtime & 0,16 & 0,20 & 0,14 & 0,11 & 0,10 & 0,14 \\
\hline Fleksibilitas & 0,11 & 0,11 & 0,21 & 0,17 & 0,30 & 0,18 \\
\hline Ekonomis & 0,35 & 0,23 & 0,37 & 0,15 & 0,27 & 0,27 \\
\hline & & & & Eigen Vector & 1,00 \\
\hline
\end{tabular}

Setelah melakukan perhitungan data dari hasil pengisian kuesoner, maka keseluruhan perhitungan memperoleh hasil sebagai berikut:

$$
\left(\begin{array}{lllll}
0,25 & 0,21 & 0,26 & 0,22 & 0,26 \\
0,49 & 0,64 & 0,60 & 0,66 & 0,60 \\
0,26 & 0,15 & 0,14 & 0,12 & 0,13
\end{array}\right) *\left(\begin{array}{l}
0,23 \\
0,17 \\
0,14 \\
0,18 \\
0,27
\end{array}\right)=\left(\begin{array}{l}
0,24 \\
0,59 \\
0,16
\end{array}\right)
$$

Dari Eigen Vector keputusan terlihat bahwa:

1. Finance memiliki bobot prioritas tertinggi yaitu 0.59

2. Warehouse Management memiliki bobot prioritas kedua yaitu 0.24

3. Travel Management memiliki bobot prioritas ketiga yaitu 0.16

Dari perhitungan akhir didapatkan bahwa Finance merupakan aplikasi yang paling di minati pada PT. RMM Solution dengan bobot nilai 0,59 atau 59\%. 


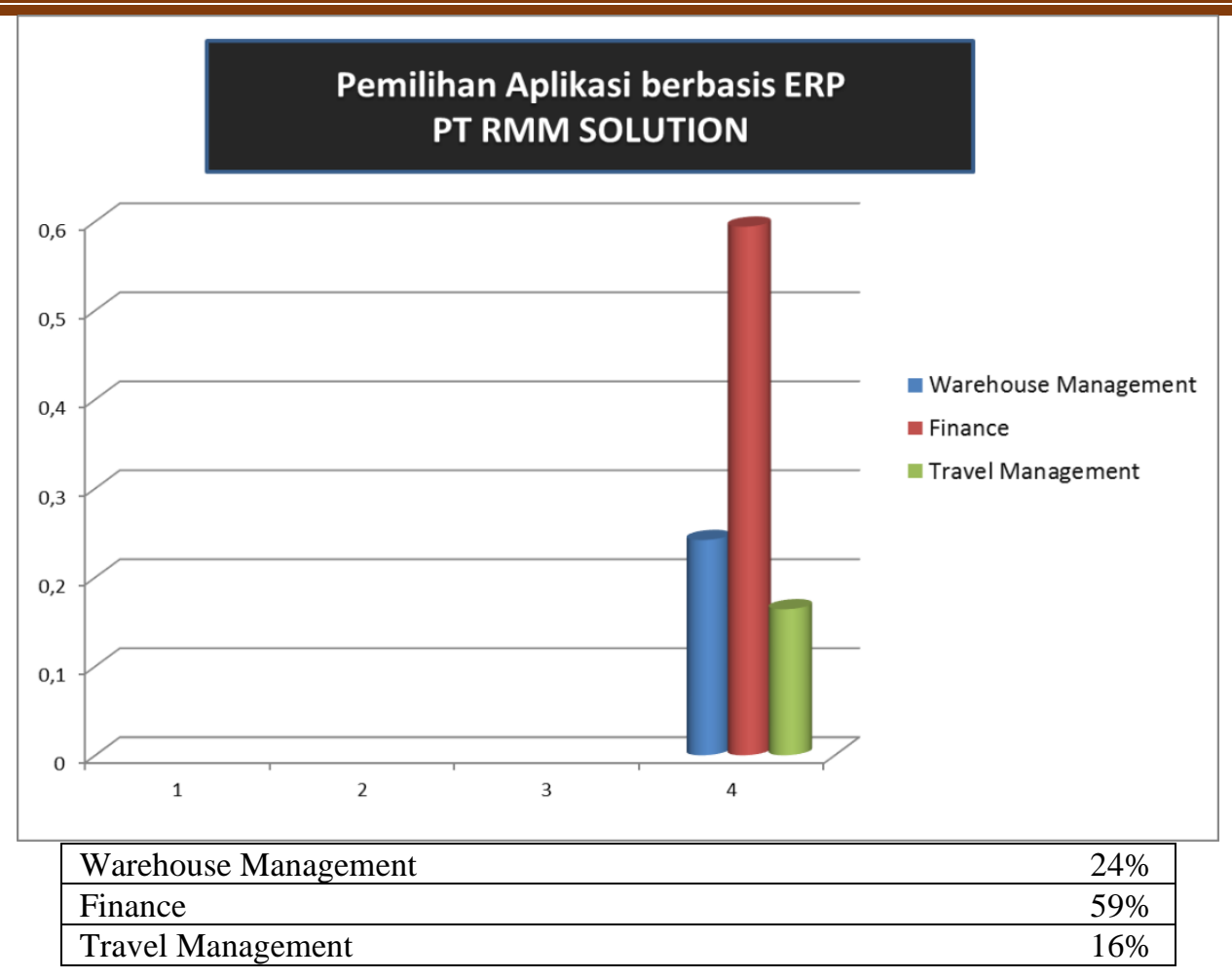

Gambar 4. Presentase Vector Eigen Keputusan

\section{KESIMPULAN DAN REKOMENDASI}

Aplikasi sistem pendukung keputusan yang dibangun dengan menggunakan metode AHP ini dapat membantu mempermudah dan mempercepat dalam menentukan aplikasi ERP, yaitu dilakukan dengan beberapa tahapan sebagai berikut: decompotition, comparative judgement, synthesis of priority dan logical consistency.

Tingkat keakuratan dalam menentukan aplikasi ERP dengan menggunakan metode AHP ini dapat dinilai dari Consistency Ratio Hierarchy / CRH < 10\%, maka hasil perhitungan dapat dinyatakan benar. Dalam perhitungan, Consistency Ratio Hierarchy / CRH adalah 0,073940701 atau 7,4\% itu artinya nilai dapat diterima dan hasil perhitungan dinyatakan benar.

Berdasarkan vector eigen keputusan, didapatkan hasil sebagai berikut :

1. Finance memiliki nilai yang tertinggi yaitu 0,5941

2. Warehouse Management memiliki nilai kedua tertinggi yaitu 0,2418

3. Travel Management memiliki nilai terendah yaitu 0,1640

Sehingga bisa disimpulkan pemilihan aplikasi berbasis ERP yang yang sesuai untuk PT. RMM Solution adalah Finance. 


\section{REFERENSI}

Asadabadi, M. R., Chang, E., \& Saberi, M. (2019). Are MCDM methods useful? A critical review of Analytic Hierarchy Process (AHP) and Analytic Network Process (ANP). Cogent Engineering, 6(1).

Khasanah, R., Raharjo, K., (2017). Analisis Penerapan Metode Target Costing Dalam Upaya Meningkatkan Efisiensi Biaya Produksi Untuk Memaksimalkan Laba ( Studi Kasus Pada Perusahaan Kecap Kuda Kaloka di Salatiga Tahun 2016 ).

Maseleno, A., Rizqi Al Akbar, M., \& Fitrian, Y. (n.d.). Dismissal Working Relationship using Analytic Hierarchy Process Method. Retrieved from https://www.researchgate.net/publication/327201007

Putra, A. A., Kusrini, K., \& Pramono, E. (2019). Sistem Pendukung Keputusan Dalam Pemilihan Control Panel Virtual Private Server Menggunakan Metode Ahp Dan Saw. Creative Information Technology Journal, 5(1), 14.

Shabbir, R., \& Ahmad, S. S. (2016). Water resource vulnerability assessment in Rawalpindi and Islamabad, Pakistan using Analytic Hierarchy Process (AHP). Journal of King Saud University - Science, 28(4), 293-299.

Suminten. (2019). Implementasi Enterprise Resource Planning (Erp) Pada Usaha Pithik Sambel Ndesso Berbasis ODOO. Jurnal PROSISKO, 6(1). Retrieved from https://ejurnal.lppmunsera.org/index.php/PROSISKO/article/view/1127

Tantangan, D., Sosial Banuprasetyo, P., \& Trisyanti, D. (2018). Revolusi Industri 4.0 Dan Tantangan Perubahan Sosial. IPTEK Journal of Proceedings Series, O(5), 22-27.

Wang, T.-K., Zhang, Q., Chong, H.-Y., \& Wang, X. (2017). Integrated Supplier Selection Framework in a Resilient Construction Supply Chain: An Approach via Analytic Hierarchy Process (AHP) and Grey Relational Analysis (GRA). Sustainability, 9(2), 289. 